\title{
The Novel Calpain Inhibitor SJA6017 Improves Functional Outcome after Delayed Administration in a Mouse Model of Diffuse Brain Injury
}

\author{
NANCY C. KUPINA, ${ }^{1}$ RATHNA NATH, ${ }^{1}$ ERIC E. BERNATH, ${ }^{1}$ JUN INOUE, \\ AZUMA MITSUYOSHI, ${ }^{2}$ PO-WAI YUEN, ${ }^{3}$ KEVIN K.W. WANG, \\ and EDWARD D. HALL ${ }^{1}$
}

\begin{abstract}
A principal mechanism of calcium-mediated neuronal injury is the activation of neutral proteases known as calpains. Proteolytic substrates for calpain include receptor and cytoskeletal proteins, signal transduction enzymes and transcription factors. Recently, calpain inhibitors have been shown to provide benefit in rat models of focal head injury and focal cerebral ischemia. The present study sought to investigate, in experiment 1 , the time course of calpain-mediated cytoskeletal injury in a mouse model of diffuse head injury by measuring the 150- and 145-kDa $\alpha$-spectrin breakdown products (SBDP). Secondly, in experiment 2, we examined the effect of early (20 min postinjury) administration of the novel calpain inhibitor SJA6017 on functional outcome measured 24 h following injury and its effect on posttraumatic $\alpha$-spectrin degradation. Lastly, in experiment 3, we examined the effect of delayed ( 4 or $6 \mathrm{~h}$ postinjury) administration of SJA6017 on 24-h postinjury functional outcome. In experiment 1 , isoflurane-anesthetized male CF-1 mice (18-22 g) were subjected to a $750 \mathrm{~g}-\mathrm{cm}$ weight drop-induced injury and were sacrificed for SBDP analysis at postinjury times of $30 \mathrm{~min}$, and 1, 2, 6, 24 and $48 \mathrm{~h}$ (plus sham). In experiments 2 and 3, mice were injured as described, and delivered a single tail vein injection of either SJA6017 $(0.3,1$, or $3 \mathrm{mg} / \mathrm{kg})$ or vehicle (administered immediately, 4 or $6 \mathrm{~h}$ postinjury [3 mg/kg]). Functional outcome was evaluated in both studies, and, in experiment 2, 24-h postinjury assessment of SBDPs was determined. Following injury, the level of SBDP 145 was significantly different from sham at 24 and $48 \mathrm{~h}$ in cortical and at $24 \mathrm{~h}$ in the hippocampal tissues and at $48 \mathrm{~h}$ in the striatum. Immediate postinjury administration of SJA6017 resulted in a dose-related improvement in 24 -h functional outcome ( $p<$ 0.05 at $3 \mathrm{mg} / \mathrm{kg}$ ). Significance was maintained after a 4-h delay of the $3 \mathrm{mg} / \mathrm{kg}$, but was lost after a 6-h delay. Despite improvement in functional outcome at $24 \mathrm{~h}$, SJA6017 did not reduce spectrin breakdown in cortical or hippocampal tissues. These results support a role for calpain-mediated neuronal injury and the potential for a practical therapeutic window for calpain inhibition following traumatic brain injury. However, measurements of regional spectrin degradation may not be the most sensitive marker for determining the effects of calpain inhibition.
\end{abstract}

Key words: calpain activation; calpain-mediated spectrin proteolysis; neuroprotection; traumatic brain injury

\footnotetext{
${ }^{1}$ Neuroscience Therapeutics, Pfizer Global Research and Development-Ann Arbor Laboratories, Ann Arbor, Michigan.

${ }^{2}$ Kobe Creative Center, Senju Pharmaceutical Co., Ltd, Hyogo, Japan.

${ }^{3}$ Neuroscience Chemistry, Pfizer Global Research and Development-Ann Arbor Laboratories, Ann Arbor, Michigan.
} 


\section{INTRODUCTION}

D ISRUPTION of intracellular calcium homeostasis is a key constituent in the pathophysiology of traumatic or ischemic brain injury. Following an injurious event, there is a massive posttraumatic calcium influx secondary to glutamate release and opening of glutamate receptorassociated and voltage-dependent calcium channels (for review, see McIntosh et al., 1997). Excessive intracellular calcium accumulation can lead to neuronal degeneration by (1) activation of various enzymes including proteases, kinases, phosphatases, and phospholipases (McIntosh et al., 1997; Siesjo et al., 1989, Verity, 1992), (2) induction of free radical release (Hall, 1998; Kontos, 1989), and (3) by mediating detrimental changes in gene expression (Bading et al., 1993; Rink et al., 1995). Evidence of increased calcium concentrations in models of traumatic brain injury (TBI) has been demonstrated by multiple laboratories (Fineman et al., 1993; Nadler et al., 1995; Nilsson et al., 1993; Shapira et al., 1989).

A principal mechanism of calcium-mediated neuronal injury is the activation of the neutral proteases known as calpains (Bartus, 1997; Kampfl et al., 1997). There are six distinct members of the calpain family, which can be divided into two groups - calpains that are tissue-specific and calpains that are ubiquitously expressed (Sorimachi et al., 1994). The two most recognized isoforms of calpain, $\mu$-calpain and $\mathrm{m}$-calpain, require $\mu \mathrm{M}$ and $\mathrm{mM}$ concentrations of calcium, respectively, for activation in vitro. However, in vivo activation of both may occur at much lower calcium concentrations (Coolican et al., 1984; Nixon, 1989; Suzuki et al., 1990). Identified proteolytic substrates of calpain include receptor proteins (EGF, $\mathrm{IP}_{3}$, and estrogen receptors), calmodulin-binding proteins ( $\mathrm{G}$ proteins, calcineurin), cytoskeletal proteins ( $\alpha$-spectrin, microtubule-associated protein 2, neurofilaments, tau), signal transduction enzymes (phospholipase $\mathrm{C}$, protein kinase $\mathrm{C}$, tyrosine phosphatase IIb), and transcription factors (c-fos, c-jun, c-myc; for reviews, see Yuen et al., 1996; Kampfl et al., 1997).

Perhaps the most studied target for calpain-mediated injury is the cytoskeleton. Indeed, several laboratories have shown that degradation of cytoskeletal proteins occurs in experimental models of stroke (Aronowski et al., 1999; Hong et al., 1994; Liebetrau et al., 1999; RobertsLewis et al., 1994), TBI (Buki et al., 1999; Kampf et al., 1996; Newcomb et al., 1997; Posmantur et al., 1996; Saatman et al., 1996a), spinal cord injury (Banik et al., 1997; Braughler and Hall, 1984; Ray et al., 1999), and experimental allergic encephalomyelitis (EAE), a model of the demyelinating disease, multiple sclerosis (for review, see Shields and Banik, 1999). While damage to cytoskeletal proteins (e.g., neurofilaments, microtubule-as- sociated protein, $\alpha$-spectrin) is evident within the first minutes following experimental TBI, the height of proteolytic activity appears to occur several hours after injury (Newcomb et al., 1997; Posmantur et al., 1994), and in the case of mild injury, occurs as late as several days (Saatman et al., 1998). This delayed and long sustained (Saatman et al., 1996a) degradation of the cytoskeleton may provide a practical therapeutic window for pharmacological calpain inhibition beyond the early moments after TBI.

Several pharmacological inhibitors of calpain have been identified including leupeptin, antipain, calpain inhibitor I and II, calpeptin, E64, AK295, MDL 28170, and PD150606 (an alpha-mercaptoacrylic acid derivative; Wang et al., 1996; for reviews, see Wang and Yuen, 1994, 1998; Yuen and Wang, 1996, 1998). The approach of calpain inhibition as a neuroprotective strategy has been validated based on the reported efficacy of calpain inhibitor II (Posmantur et al., 1997a), AK295 (Bartus et al., 1994; Saatman et al., 1996a,b), and MDL 28170 (Li et al., 1998; Markgraf et al., 1998) in models of traumatic and ischemic brain injury. In the case of MDL 28170, it has been reported to reduce infarct size in rats subjected to temporary middle cerebral artery occlusion even when administered $6 \mathrm{~h}$ after onset of ischemia (Markgraf et al., 1998). However, the therapeutic window for calpain inhibition in TBI models has not been reported.

More recently, a new reversible peptide aldehyde inhibitor of calpain, SJA6017 (Fig. 1), has been introduced (Fukiage et al., 1997). SJA6017 is similar in many ways to others of it's class (MDL 28170, calpain inhibitor I and II), yet, based on unpublished data, perhaps less cytotoxic than the MDL 28170 compound. For example, in a human neuroblastoma SH-SY5Y cell based assay which measures lactate dehydrogenase (LDH) release as a measure of cell toxicity (Posmantur et al., 1997b), the $50 \%$ lethal concentration $\left(\mathrm{LC}_{50}\right)$ for SJA6017 was $>500$ $\mu \mathrm{M}$ compared to $74 \mu \mathrm{M}$ for MDL 28170 . Similar results were also seen in a rat cerebellar granular neuron based assay (Nath et al., 1998) where the LC50 for SJA6017 was $>500 \mu \mathrm{M}$ compared to $100 \mu \mathrm{M}$ for MDL 28170 (K.K.W. Wang, R. Nath, and M. Fields, unpublished data).

The presently reported study involved an examination of SJA6017 using a mouse model of moderately severe, diffuse head injury (Hall et al., 1995; Fig. 2). To our knowledge, this is the first time a calpain inhibitor has been studied in a model of diffuse traumatic brain injury, as well as the first to employ mice. Previous studies have been conducted in rat models of focal injury such as controlled cortical impact (Kampfl et al., 1996, 1997; Posmantur et al., 1997a) or in temporal fluid percussion (Saatman et al., 1996b; 2000). The design of our study 


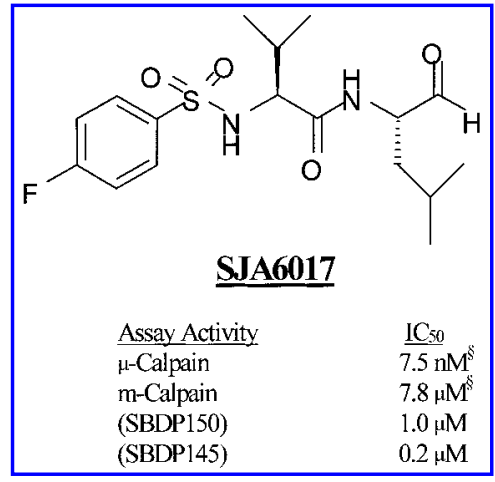

FIG. 1. Chemical structure of the calpain inhibitor SJA6017 and $50 \%$ inhibitory concentration $\left(\mathrm{IC}_{50}\right)$ activity levels in relevant assays. $\mathrm{IC}_{50}$ assay for SBDP 150 and SBDP 145 was done in triplicate using Molt-4 (human leukemic) cells that were preincubated $1 \mathrm{~h}$ with varying concentrations of SJA6017. Endogeneous calpain was activated by addition of the calcium ionophore A23187, and, following incubation, the proteins were extracted and concentrations were determined. Protein samples were run on SDS/PAGE and transferred onto PVDF membranes, which were probed with anti- $\alpha$-spectrin antibody (Chemicon), followed by a standard development protocol. Densitometric analysis of the 150- and 145-kDa bands were preformed with the NIH program Image 1.5; mean values were plotted and the concentration of SJA6017 that reduced the intensity of the 150 - and $145-\mathrm{kDa}$ bands by $50 \%$ was determined. ( ${ }^{\S}$ Assays referenced in Wang et al., 1996).

sought first to establish a time course of calpain-mediated cytoskeletal degradation by measuring $\alpha$-spectrin breakdown over the first $48 \mathrm{~h}$ postinjury. $\alpha$-Spectrin is a 280-kDa nonerythroid cytoskeletal protein that provides structural support to membranes. It is also a substrate for calpain, which can cleave $\alpha$-spectrin at tyrosine 1176 to yield a 150-kDa fragment (SBDP150) or at glycine 1230 to yield a 145-kDa fragment (SBDP145; Harris and Morrow, 1988). The second aim was to establish a dose-response analysis of early (20 min postinjury) administration of SJA6017 in terms of improvement in 24-h behavioral response. After definition of a dose that promoted improved functional outcome, the effect of SJA6017 on posttraumatic $\alpha$-spectrin degradation was examined. The third aim was to evaluate the therapeutic, posttraumatic, time window by examining the efficacy of delayed (4 or 6 h postinjury) administration of SJA6017.

\section{MATERIALS AND METHODS}

All procedures were carried out in strict compliance with the Institutional Animal Care and Use Committee of Parke-Davis Pharmaceutical Research.

\section{Mouse Model of Diffuse Head Injury}

The mouse head injury method was first introduced by Hall et al. (1995) and was employed as described previously except for the addition of an anesthetic component. Male CF-1 mice (Charles River, Portage, MI), weighing $17-21 \mathrm{~g}$, were fed ad libitum prior to injury. Mice were briefly anesthetized in a chamber containing $2.5 \%$ isoflurane (Anaquest) balanced with air and oxygen. Each mouse was grasped by the dorsal skin of the neck, and its head placed upon the base of the injury device. A round, flat, 6-mm diameter Teflon impounder was positioned firmly against the top of the head, centered between the ears and eyes, and a 50-g stainless steel weight was released at a height of $15 \mathrm{~cm}$, producing a velocity calculated at $171.5 \mathrm{~cm} / \mathrm{sec}$. The resulting moderately severe injury creates a pattern of diffuse degeneration, which is diversely projected into the brain with variable intensity (Fig. 2). To prevent posttraumatic hypothermia, injured mice were placed in a Hova-Bator incubator (model 1583, Randall Burkey Co.) at $37^{\circ} \mathrm{C}$ until consciousness was regained (20-30 $\mathrm{min})$.

\section{Experimental Design}

Three separate experiments were performed. Experiment 1 measured $\alpha$-spectrin degradation in cortex, hippocampus and striatum over a 48 -h postinjury time course. Experiment 2 examined the dose-response for the effect of immediate postinjury administration of SJA6017 on functional recovery and $\alpha$-spectrin degradation measured $24 \mathrm{~h}$ following injury. Experiment 3 looked at the effect of delayed administration of SJA6017 on functional recovery measured $24 \mathrm{~h}$ following injury.

\section{Western Immunoblotting of $\alpha$-Spectrin Degradation Products}

In experiment 1 and 2 , spectrin degradation was quantified by Western immunoblots as previously described (Nath et al., 1996), and expressed as the ratio of 150- or $145-\mathrm{kDa}$ spectrin fragment to intact spectrin. The mice were deeply anesthesia with isoflurane, killed and their brains immediately removed and briefly rinsed in chilled saline $(0.9 \%$ sodium chloride for irrigation, USP). Tissues from each brain, representing cortex, striatum and hippocampus, were dissected on a chilled stage and then frozen in ice cold isopentane $\left(-40^{\circ} \mathrm{C}\right)$ and stored at $-80^{\circ} \mathrm{C}$. Frozen brain tissue was powdered with precooled mortar-pestle over dry ice. Approximately $50 \mathrm{mg}$ of powdered tissue was resuspended in triton lysis buffer [1\% triton, $20 \mathrm{mM}$ TrisHCL, $150 \mathrm{mM} \mathrm{NaCl}, 5 \mathrm{mM}$ EDTA, $1 \mathrm{mM}$ DTT and protease inhibitor cocktail (Boehringer Mannheim)]. The samples were placed on ice for $5 \mathrm{~min}$ with intermittent vortexing. The lysate was 


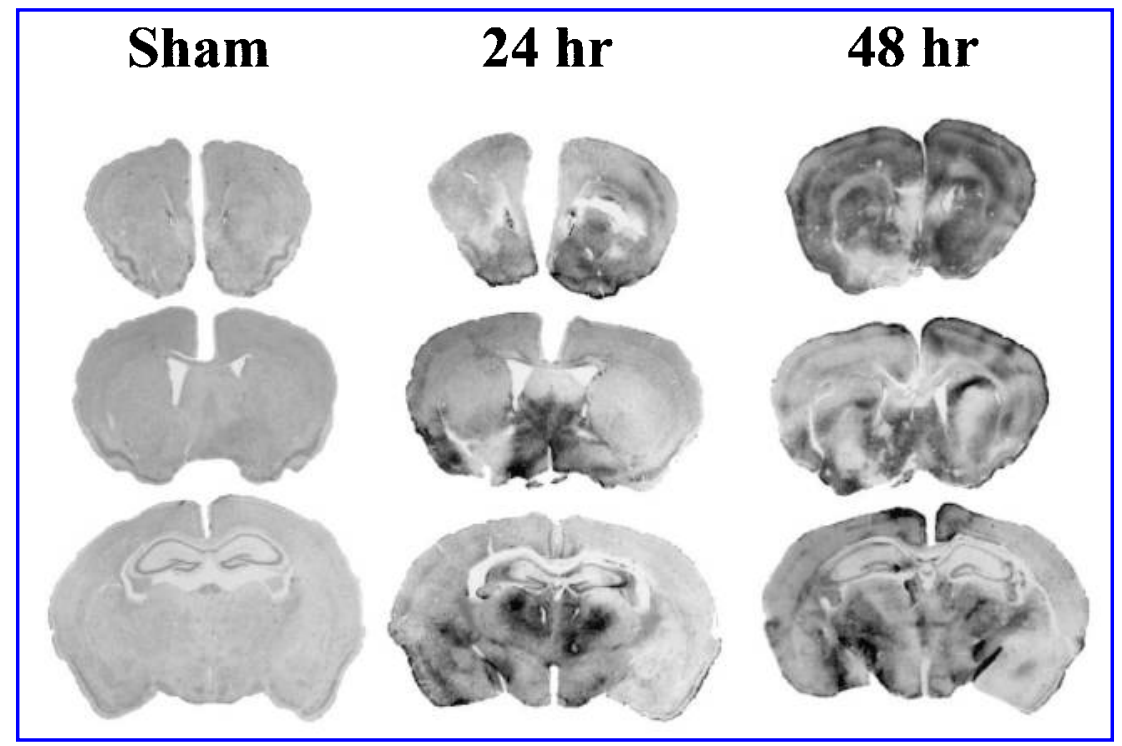

FIG. 2. Sample time course of diffuse neuronal degeneration in male mice following diffuse head injury as measured by aminocupric silver staining (shown in black), a marker for neuronal degeneration and debris (Fix et al., 1996; de Olmes et al., 1994; Switzer, 2000). Neurohistology was performed by NeuroScience Associates (Knoxville, TN). Brains were embedded together in a single block of geletin, freeze sectioned at $35 \mu \mathrm{M}$, and stained for degeneration using the amino cupric silver method of de Olmos et al., 1994) and counterstained with neutral red to reveal normal cell bodies. The resulting, moderately severe, injury creates a pattern of diffuse degeneration, which is diversely projected into the brain with variable intensity. The progression and degree of neuronal degeneration appears to occur over a number of days following TBI.

cleared by centrifugation at $20,000-\times g$ for $15 \mathrm{~min}$ at $4^{\circ} \mathrm{C}$. Protein concentration in the cleared lysate was determined using a modified Lowry assay (Bio-Rad). Each lane was loaded with $20 \mu \mathrm{g}$ of protein and run on SDS/PAGE [4-20\% (w/v) acrylamide] with Tris/glycine running buffer system and then transferred to a nitrocellulose membrane using a semi-dry electrotransferring unit (Bio-Rad) at $20 \mathrm{~mA}$ for $2 \mathrm{~h}$. The blots were probed with an anti- $\alpha$-spectrin antibody (monoclonal, Affi Labs, U.K.) and developed in a linear range using nitro blue tetrazolium and 5-bromo-4-chloro-3-indolyl phosphate. Densitometric analysis of Western blots was done using a color scanner (Umax UC630) and the NIH program, Image 1.5.

Western blot data are expressed as mean \pm SE. Injuryinduced increases in the ratio of SBDP 150 or 145/intact spectrin were compared to control animals using a oneway ANOVA followed by a Bonferroni Multiple Comparisons test for selected pairs. A $p$ value of 0.05 compared to sham was considered significant.

\section{SJA6017 Administration}

In experiment 2 , beginning approximately $20 \mathrm{~min}$ postTBI, 17-18 mice each were randomly assigned to one of four groups, each receiving a single tail-vein injection of SJA6017 at $0.3,1$, or $3 \mathrm{mg} / \mathrm{kg}$ or vehicle. SJA 6017 was dissolved in $88 \%$ propylene glycol, $10 \%$ ethyl alcohol, and $2 \%$ benzyl alcohol at varying concentrations to accommodate a dosing volume of $0.05 \mathrm{~mL}$ per animal. In experiment 3 , beginning 4 or $6 \mathrm{~h}$ post-TBI, 15 mice each were randomly assigned to one of two groups, each receiving a single tail-vein injection of either SJA 6017 (3 $\mathrm{mg} / \mathrm{kg} ; 60 \mathrm{mg} / \mathrm{mL} / \mathrm{kg} ; 0.05 \mathrm{~mL}$ per injection) or vehicle. SJA 6017 was prepared as described in experiment 2.

\section{Assessment of Functional Outcome}

In experiment 2 and 3, functional outcome was assessed by means of a previously described grip score (Hall, 1995) with modifications. Briefly, at $24 \mathrm{~h}$ postTBI, the mice were suspended by their tails and their forepaws were placed in contact with a taut string stretched $40 \mathrm{~cm}$ above a padded surface. Once the forepaws were in contact, the tails were released and the mice were evaluated for (1) length of time they remained on the string (with a 30-sec maximum) and (2) their performance while on the string. Both measurements were tallied and then combined into a single grip score, with a total score of 6 representing the best measurable outcome (Table 1).

In experiment 2 and 3, data are expressed as mean \pm SE. Grip scores were compared, in study 1, by Kruskal Wallis nonparametric ANOVA and posthoc Mann-Whit- 
Table 1. Grip Score Scale for the Measurement of Functional Outcome in Mice following TBI

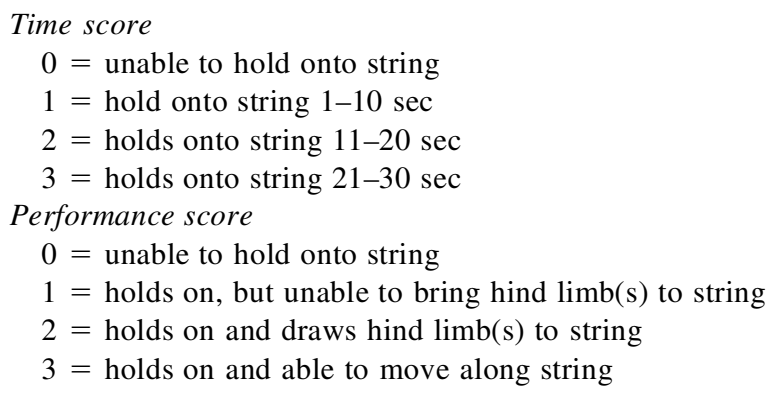

Time and performance scores for each mouse were combined into a single grip score with a combination of six representing highest measurable outcome.

ney test (Fig. 5A). An analysis of mice exhibiting the best measurable outcome score compared to those of partial scores was measured by $\chi^{2}$ for trend (Fig. 5B). In experiment 3, grip scores were compared by a Mann-Whitney test (Fig. 7A), and an analysis of mice exhibiting the best measurable outcome score compared to those of partial scores was measured by Fisher's exact test (Fig. 7B).

\section{RESULTS}

\section{Time Course of $\alpha$-Spectrin Degradation} Following Traumatic Brain Injury

The time course of cortical $\alpha$-spectrin breakdown (generation of SBDP150 and SBDP145) in mice subjected to diffuse head injury is demonstrated by Western immunoblot in Figure 3. The SBDP150 and SBDP145 bands were densitometrically measured and then normalized to intact $\alpha$-spectrin ( $280 \mathrm{kD}$ level), shown in Figure 4. Cortical levels of SBDP 145 were significantly different than sham at 24 and $48 \mathrm{~h}$ postinjury. Significant SBDP 145 increases in the striatum were present only at $24 \mathrm{~h}$ postinjury, while hippocampal levels of SBDP 145 reached significance by $48 \mathrm{~h}$ following injury. Although a similar trend towards time course increases in SBDP 150 for the three different brain regions can be appreciated, there were no significant differences in SBDP 150 levels in cortex, striatum, or hippocampus.

\section{Effect of Immediate Postinjury Administration of SJA6017 on Functional Outcome}

Figure 5A illustrates the dose-response effect of SJA6017 on functional outcome at $24 \mathrm{~h}$ following injury in mice that received an immediate, postinjury, tail-vein injection of SJA6017. Functional outcome was enhanced in a dose-dependent manner, with a significant improvement in grip score seen at the $3 \mathrm{mg} / \mathrm{kg}$ dose (nonparametric ANOVA Kruskal-Wallis, $p=0.0475$; MannWhitney test compared to sham, $p<0.05$ ). Similarly, drug-treated mice displayed a dose-dependent increase in the incidence of "best outcome" scores when compared to vehicle-treated mice $\left(\chi^{2}, p=0.0024\right.$; Fig. 5B).

\section{Effect of SJA6017 on Posttraumatic $\alpha$-Spectrin Degradation}

Cortical and hippocampal tissues were harvested for measurement of SBDPs at $24 \mathrm{~h}$ postinjury from the brains of mice receiving $3 \mathrm{mg} / \mathrm{kg}$ of SJA6017 in the dose response study (Fig. 5). Striatal tissues were not evaluated, based upon time course data indicating low SBDP levels $24 \mathrm{~h}$ following injury (Fig. 4). Figure 6 is a summary of Western immunoblots that were densitometrically measured and normalized to intact $\alpha$-spectrin (280-kD level). Despite a beneficial effect on functional outcome,
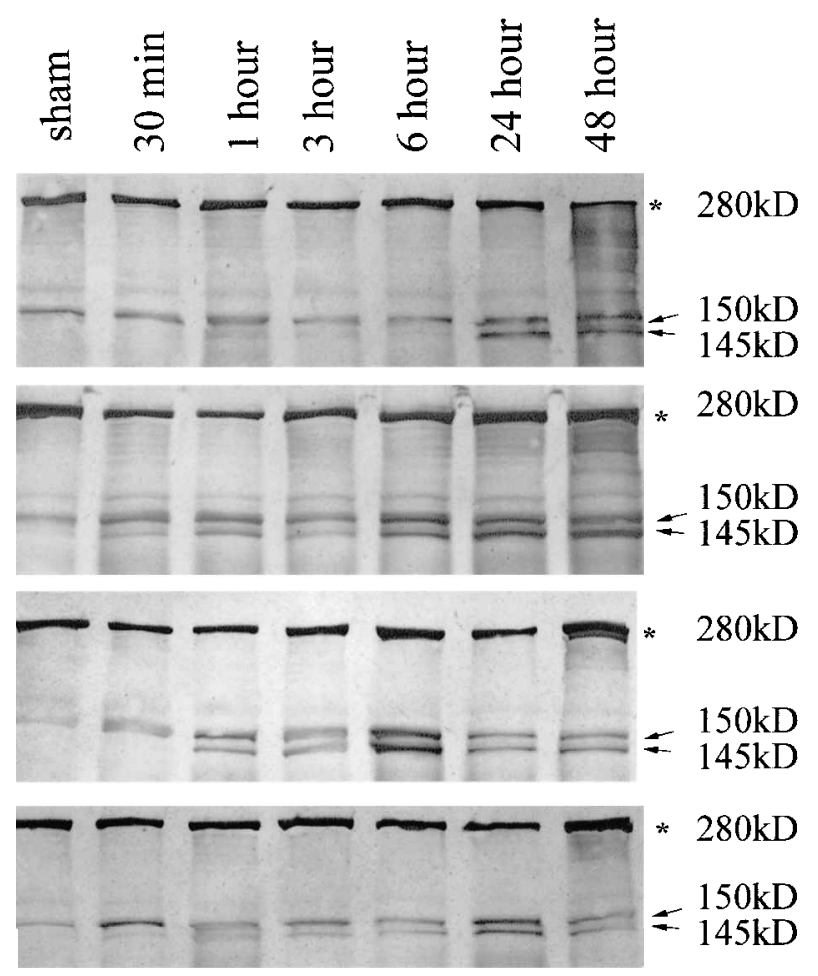

\section{Cortex $(\mathrm{N}=4)$}

FIG. 3. Western immunoblots showing the time course of $\alpha$ spectrin breakdown products, SBDP150 and SBDP145, in the mouse cortex following TBI. Intact $\alpha$-spectrin is represented by the $280-\mathrm{kD}$ band ( $n=4$ mice/group). 


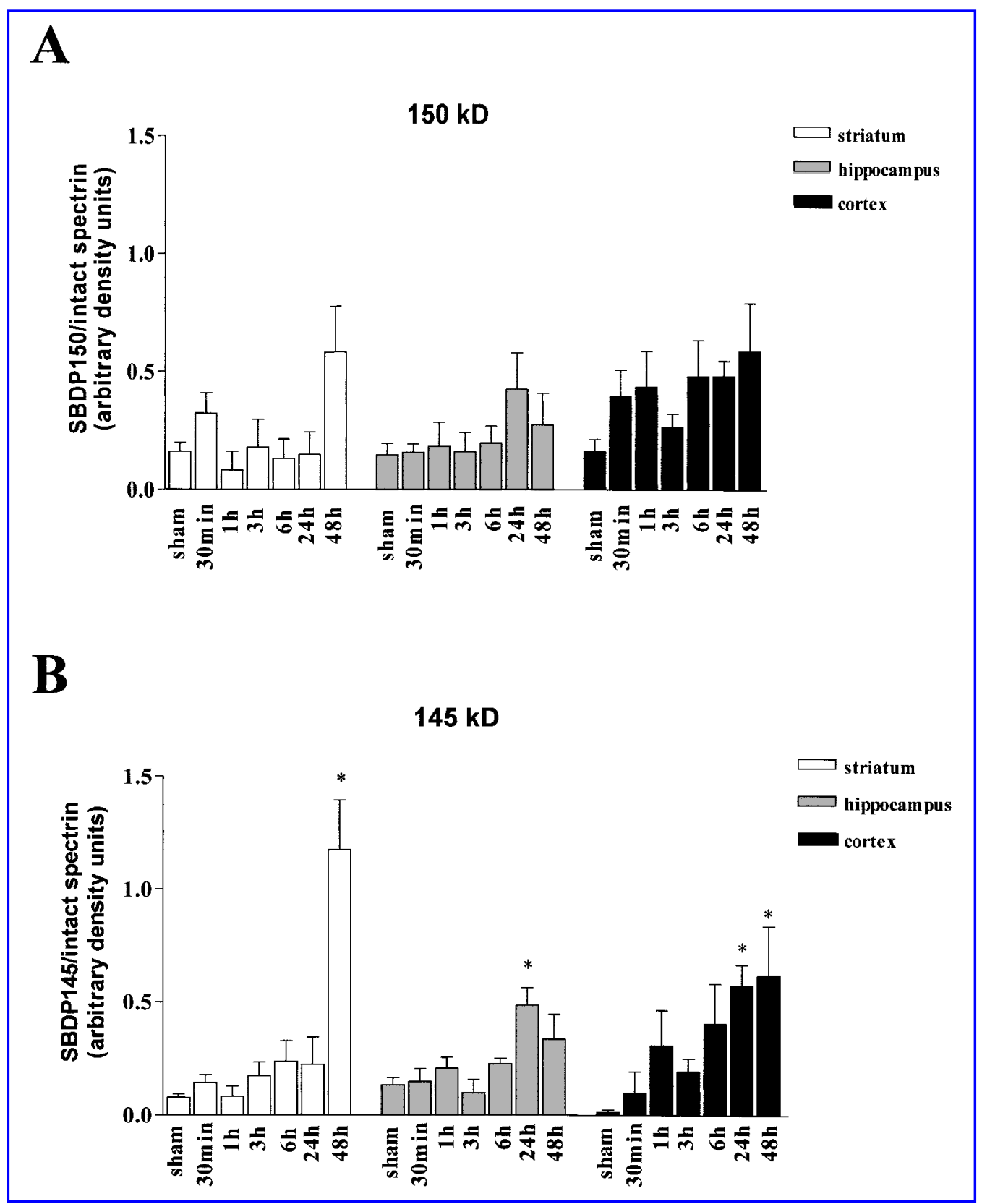

FIG. 4. Summary graph of the Western immunoblot time course of SBDP150 (A) and SBDP145 (B) in the mouse hippocampus, striatum, and cortex following TBI (mean \pm SE). Data is densitometrically measured and expressed as a ratio of SBDP/intact $\alpha$ spectrin $(280 \mathrm{kD}) .{ }^{*} p<0.05$ compared to sham $(n=4$ mice/group).

SJA6017 did not attenuate the levels of SBDPs in cortical or hippocampal tissue.

\section{Effect of Delayed Postinjury Administration of SJA6017 on Functional Outcome}

Twenty-four hours following head injury, mice that received a 4-h postinjury dose of $3 \mathrm{mg} / \mathrm{kg} \mathrm{SJA6017,} \mathrm{had}$ significant improvement in functional outcome compared to vehicle-treated mice (Mann-Whitney test, $p<0.05$; Fig. 7A). The incidence of a head-injured mouse receiving a score of best outcome was 4.5 times greater in the drug treated mice than in time-matched, vehicle-treated mice (Fisher's Exact test, $p<0.01$; Fig. 7B). However, both of these effects were lost when SJA6017 was withheld until $6 \mathrm{~h}$ postinjury (Fig. 7A,B). 


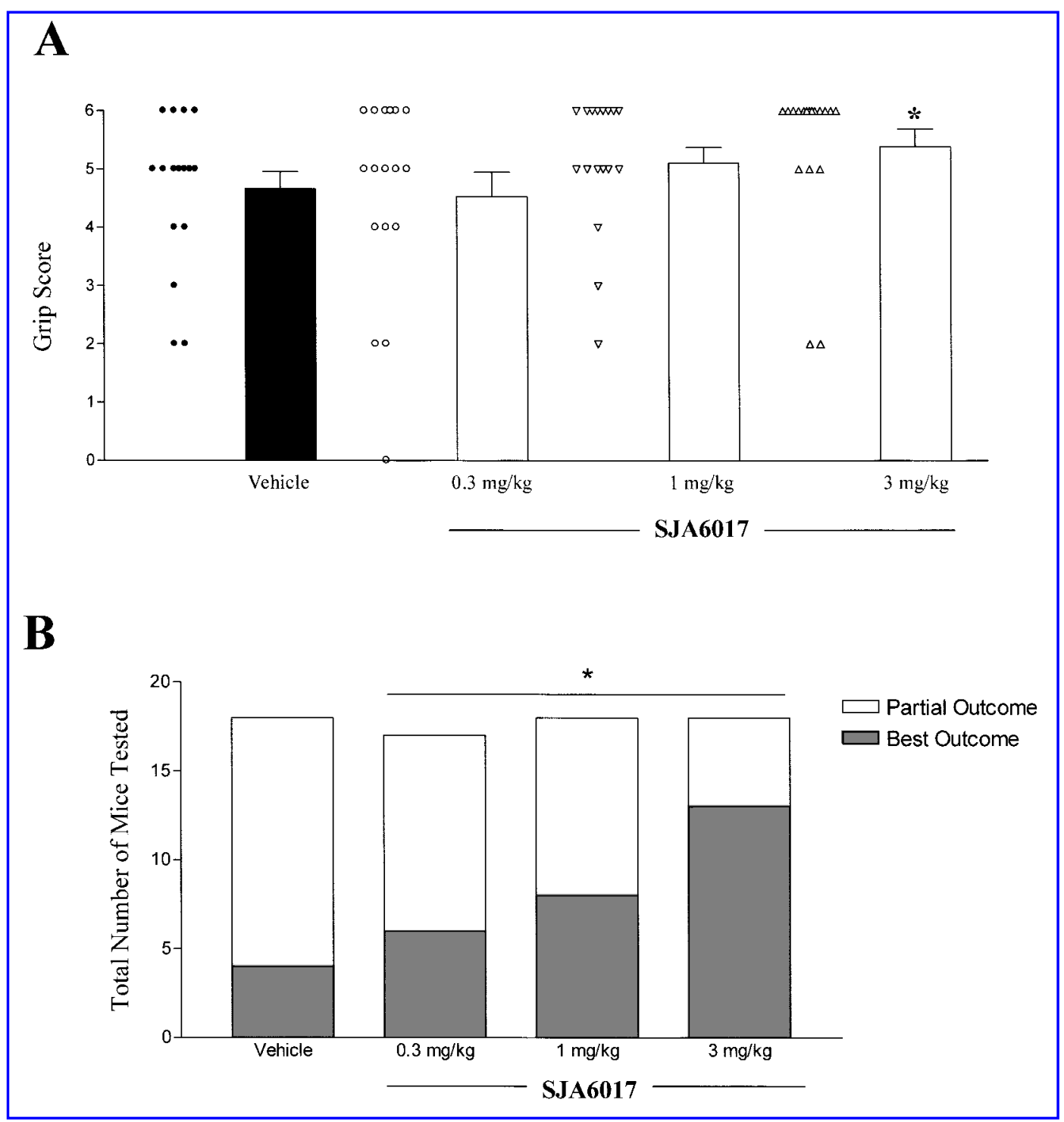

FIG. 5. (A) Dose response curve showing the ability of immediate postinjury administration of SJA6017 to improve functional outcome in mice $24 \mathrm{~h}$ following TBI (nonparametric ANOVA, $p=0.0475$, mean $\pm \mathrm{SE}$ ). $*$ Posthoc test, $p<0.05$ compared to sham ( $n=17-18$ mice/group). (B) Graph of a contingency table analysis indicating the number of mice in each treatment group exhibiting the best outcome score against those of partial scores $\left(\chi^{2}\right.$ for trend, $\left.p=0.0024\right)$.

\section{DISCUSSION}

The approach of calpain inhibition as a therapeutic strategy for traumatic brain injury is based, in large part, upon the desire to impede the occurrence of delayed axonal injury resulting from the calcium-mediated cascade of events following an injurious insult to the brain (Buki et al., 1999; Povlishock et al., 1999). Calcium-mediated cytoskeletal damage can lead to disruption in axonal transport, structural collapse and subsequent retrograde neuronal cell death. However, calpain activation and cytoskeletal degradation also occurs in neuronal cell bodies and dendrites. In either event, antibodies recognizing the breakdown products of ( $\alpha$-spectrin, a substrate for calpain-mediated proteolysis, have been used as a tool to identify cytoskeletal damage associated with calpain activation (Kampfl et al., 1996; Posmantur et al., 1997a; Roberts-Lewis and Siman, 1993). In models of focal brain injury, these antibodies have been employed to establish the early presence of SBDP in areas of primary tissue injury and, at later postinjury time points, have also provided evidence for SBDP in areas of the brain distal from primary focal insult (Saatman et al., 1996a).

Utilizing a model of diffuse brain injury, we, too, report significant increases in SBDP, but only at time points beginning $24-48 \mathrm{~h}$ postinjury, likened to the later, sec- 


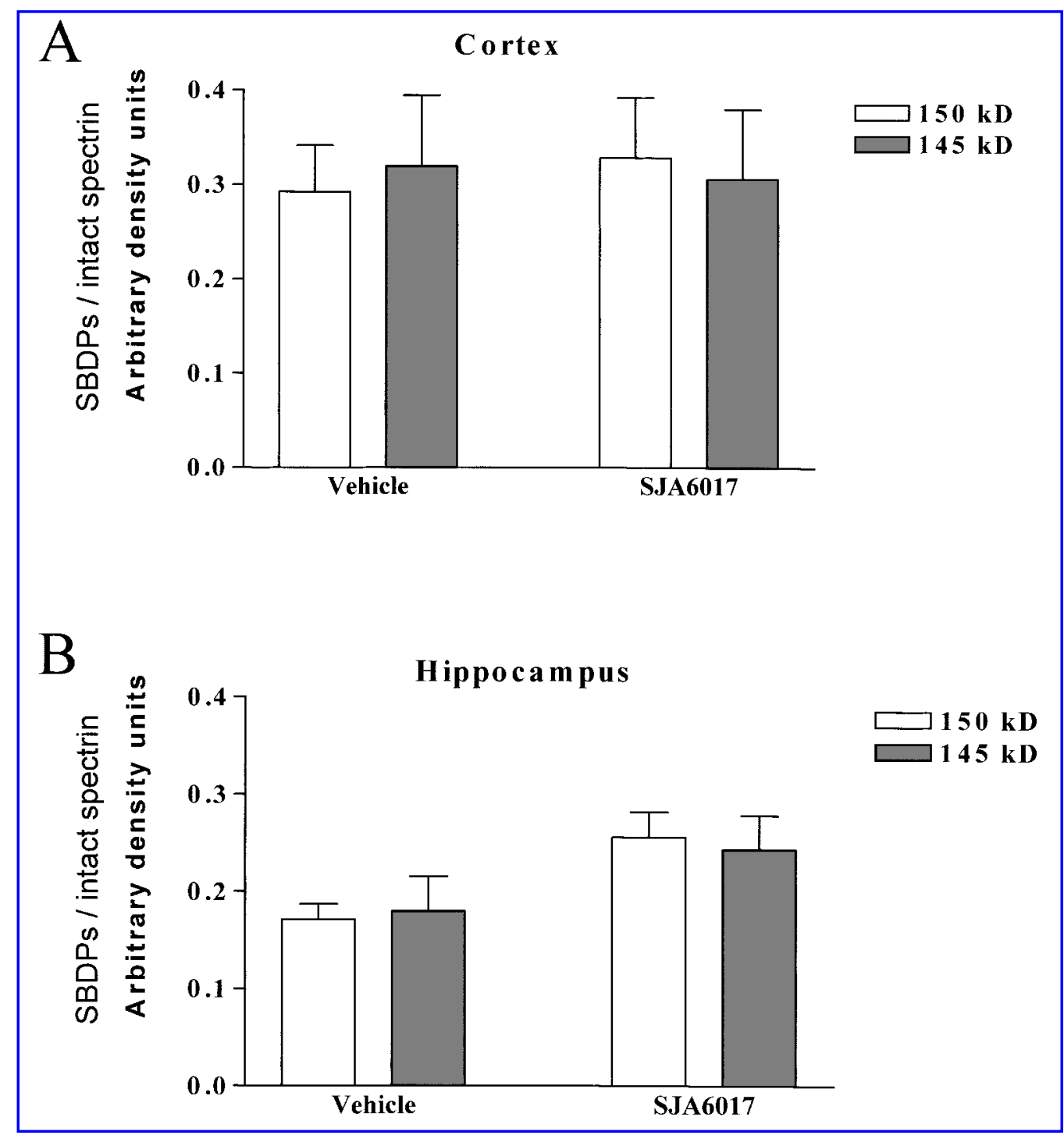

FIG. 6. Summary graph of Western immunoblots measuring SBDP150 and SBDP145 in TBI mouse cortex (A) and hippocampus (B) $24 \mathrm{~h}$ after receiving $3 \mathrm{mg} / \mathrm{kg}$ of SJA6017 immediately postinjury (mean $\pm \mathrm{SE}$ ). Data is densitometrically measured and expressed as a ratio of SBDP/intact $\alpha$-spectrin ( $280 \mathrm{kD} ; n=13 \mathrm{mice} / \mathrm{group})$.

ondary phase of calpain-mediated spectrin proteolysis seen in focal brain injury models. Povlishock and colleagues (Buki et al., 1999), employing a similar model of diffuse brain injury in rats, have provided compelling evidence (via ultrastructural, immunohistochemical examination with antibodies to SBDP and RMO-14, a marker for neurofilament compaction) for delayed, progressive calpain-mediated spectrin proteolysis. In the clinical setting, there is also evidence to support secondary axonal injury, which is believed to occur over a period of 12 or more hours (Blumbergs et al., 1995; Christman et al., 1994; Gentleman et al., 1993; Grady et al., 1993). McCracken and colleagues (McCracken et al.,
1999) have recently described SBDPs and neurofilament protein degradation in the corpus callosum of patients suffering blunt head injury at time points greater than 24 $\mathrm{h}$ following injury (compared to control subjects), furthering the suggestion that calpain-mediated damage to the cytoskeleton is a likely contributor to axonal injury in human head trauma. The reported efficacy of SJA6017 in our present study is believed to be the first demonstration of a calpain inhibitor having beneficial effects in a primarily diffuse injury paradigm. Significant improvement in functional outcome was demonstrated following immediate post-injury administration, as well as after a 4-h delay in treatment. This type of therapeutic 


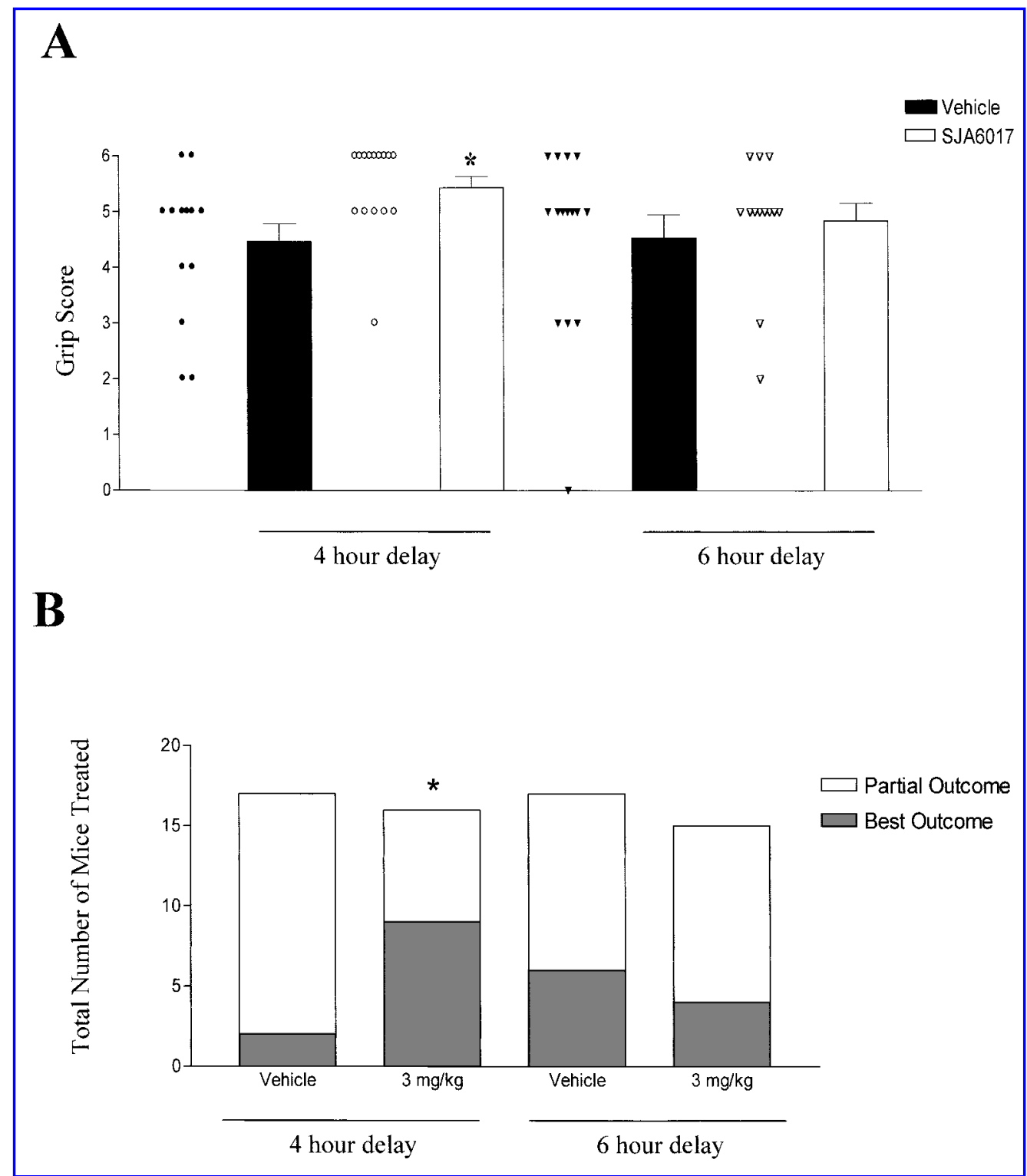

FIG. 7. (A) Graph showing improved functional outcome $24 \mathrm{~h}$ following TBI in mice receiving a 4-h delayed, postinjury, tailvein injection of SJA6017 (3 mg/kg), but no improvement in outcome following a 6-h delayed administration of SJA6017 (mean \pm SE). $* p<0.05$ compared to time-matched vehicle control ( $n=15-16$ mice/group). (B) Graph of a contingency table analysis indicating the number of mice in each treatment group exhibiting the best outcome score against those of partial scores. $* p<$ 0.05 between the 4-h delayed vehicle and drug-treated groups (Fisher's exact test).

window has been demonstrated in a model of focal cerebral ischemia where 6-h delayed administration of the calpain inhibitor MDL 28170 was shown to be protective (Markgraf et al., 1998).

Interestingly, the beneficial behavioral effects of SJA6017, measured $24 \mathrm{~h}$ postinjury, were not accompanied by a quantifiable effect on $\alpha$-spectrin degradation in cortical and hippocampal regions. $\alpha$-Spectrin degradation was equal for both treated and untreated brain-injured mice, despite significantly different behavioral outcome profiles for the same two treatment groups. One possible explanation for not seeing lower levels of SBDPs in the TBI mice receiving SJA6017 might be that the $24 \mathrm{~h}$ postinjury time point chosen may not be the most sensitive for seeing significant differences in SBDPs. It may be that postinjury time points of $48 \mathrm{~h}$ or later may provide better reflections of calpain inhibition. An additional issue to consider is the choice of brain regions in which SBDPs were measured. Because of the diffuse and uneven nature of neuronal degeneration in the cortex, hip- 
pocampus and striatum in our model, the western immunoblot analysis of calpain-mediated cytoskeletal damage may not be sensitive enough to detect the early inhibition of $\alpha$-spectrin degradation when measured in large portions of these brain regions. In other words, drug effects on axonal cytoskeletal preservation may be simply diluted out.

The lack of effect of SJA6017 on SBDP inhibition at doses that promote functional improvement is not unprecedented. Saatman and colleagues have recently demonstrated a similar finding with the calpain inhibitor AK295 (Saatman et al., 2000). While AK295 was previously shown to attenuate motor and cognitive deficits following lateral fluid percussion brain injury in rats (Saatman et al., 1996b), in separately treated animals, there was no evidence that doses of AK295 which enhanced behavioral recovery could reduce calpain-mediated spectrin proteolysis or overt cortical damage (Saatman et al., 2000). These investigators have postulated that this lack of quantifiable SBDP effect, despite positive functional outcome, might be due to multiple explanations. First of all, calpain inhibition may be occurring in regions within the brain that were beyond the capacity of their present study. Secondly, because calpain plays a role in many intracellular events, it is quite possible that the behavioral efficacy noted might be a result of the protection of calpain proteolytic substrates other than the more commonly measured cytoskeletal break down products. These alternative targets for calpain include receptor and calciumbinding proteins, signal transduction enzymes and/or transcription factors (Kampfl et al., 1997; Yuen et al., 1996).

As a final point, it should be noted that caspase 3 activation, in addition to that of calpain, can contribute to $(\alpha$-spectrin proteolysis, although caspase 3 activity only generates the $150-$, but not the $145-\mathrm{kD}$ band (Wang et al., 2000). Thus, in the case of the time-related increase in the $150-\mathrm{kD}$ SBDP, caspase 3 and calpain may both play a degradative role. However, by $24-h$, at which time our behavioral outcome assessment was made, the increase in the $145-\mathrm{kD}$ SBDP is quantitatively much more convincing than that of the $150-\mathrm{kD}$ fragment. Therefore, at least during the first $24 \mathrm{~h}$ postinjury, it seems likely that calpain activation is quantitatively more important than caspase 3. Moreover, SJA6017 does not inhibit caspase 3 or, for that matter, caspase 1 (i.e., interleukin-converting enzyme; a.k.a. ICE), and it does not possess any hypothermic effects (Senju Pharmaceuticals, Ltd., unpublished data). These facts, taken together, strongly support the conclusion that the beneficial effects of SJA6017 on 24-h behavioral outcome are, almost certainly, related to calpain inhibition, despite the lack of a demonstrable decrease in posttraumatic spectrin degradation at that time point.

\section{REFERENCES}

ARONOWSKI, J., CHO, K.-H., STRONG, R., et al. (1999). Neurofilament proteolysis after focal ischemia: when do cells die after experimental stroke? J. Cereb. Blood Flow Metab. 19, 652-660.

BADING, H., GINTY, D.D., and GREENBERG, M.E. (1993). Regulation of gene expression in hippocampal neurons by distinct calcium signaling pathways. Science 260, 181-186.

BANIK, N.L., MATZELLE, D.C., GANTT-WILFORD, G., et al. (1997). Increased calpain content and progressive degradation of neurofilament protein in spinal cord injury. Brain Res 752, 301-306.

BARTUS, R.T. (1997). The calpain hypothesis of neurodegeneration: evidence for a common cytotoxic pathway. Neuroscientist 3, 314-327.

BARTUS, R.T., HAYWARD, N.J., ELLIOT, P.J., et al. (1994). Calpain inhibitor AK295 protects neurons from focal ischemia. Effects of postocclusionintra-arterialadministration. Stroke 25, 2265-2270.

BLUMBERGS, P.C., SCOTT, G., MANAVIS, J., et al. (1995). Topography of axonal injury as defined by amyloid precursor protein and the sector scoring method in mild and severe closed head injury. J. Neurotrauma 12, 565-572.

BRAUGHLER, J.M. and HALL, E.D. (1984). Effects of multidose methylprednisolonesodium succinate administration on injured cat spinal cord neurofilament degradation and energy metabolism. J. Neurosurg. 61, 290-295.

BUKI, A., SIMAN, R., TROJANOWSKI, J.Q., et al. (1999). The role of calpain-mediated spectrin proteolysis in traumatically induced axonal injury. J. Neuropathol. Exp. Neurol. 58, 365-375.

CHRISTMAN, C.W., GRADY, M.S., WALKER, S.A., et al. (1994). Ultrastructural studies of difuse axonal injury in humans. J. Neurotrauma 11, 173-187.

COOLICAN, S.A. AND HATHAWAY, D.R. (1984). Effect of L-alpha-phosphatidylinositol on a vascular smooth muscle calcium-dependent protease. Reduction of the calcium requirement for autolysis. J. Biol. Chem. 259, 11627-11630.

FINEMAN, I., HOVDA, D.A., SMITH, M., et al. (1993). Concussive brain injury is associated with prolonged accumulation of calcium: a ${ }^{45} \mathrm{Ca}$ autoradiographic study. Brain Res. 624, 94-102.

FIX, A.S., ROSS, J.F., STITZEL, S.R. et al. (1996). Integrated evaluation of central nervous system lesions: stains for neurons, astrocytes, and microglia reveal that spatial and temporal features of MK-801-induced neuronal necrosis in the rat cerebral cortex. Toxicol. Pathol. 24, 291-304.

FUKIAGE, C., AZUMA, M., NAKMURA, Y., et al. (1997). SJA 6017, a newly synthesized peptide aldehyde inhibitor of calpain: amelioration of cataract in cultured rat lenses. Biochem. Biophys. Acta 1361, 304-312. 
GENTLEMAN, S.M., NASH, M.J., SWEETING, C.J., et al. (1993). $\beta$-Amyloid precursor protein ( $\beta$-APP) as a marker for axonal injury after head injury. Neurosci Lett 160, $139-144$.

GRADY, M.S., McLAUGHLIN, M.R., CHRISTMAN, C.W., et al. (1993). The use of antibodies against neurofilament subunits for the detection of diffuse axonal injury in humans. J Neuropathol Exp Neurol 52, 143-152.

HALL, E.D. (1998). Antioxidant pharmacotherapy, in: CerebrovascularDisease: Pathophysiology, Diagnosis, and Management. M.D. Ginsberg and J. Bogousslavsky (eds), Blackwell Science: Malden, MA, pps. 710-720.

HALL, E.D. (1995). The mouse head injury model: utility in the discovery of acute cerebroprotective agents, in: Central Nervous System Trauma Research Techniques. S.T. Ohnishi and T. Ohnishi (eds), CRC Press: Boca Raton, FL, pps. 213-223.

HARRIS, A.S. AND MORROW, J.S. (1988). Proteolytic processing of human brain alpha spectrin (fodrin), identification of a hypersensitive site. J. Neurosci. 8, 2640-2651.

HIRAI, S., KAWASAKI, H., YANIV, M., et al. (1991). Degradation of transcription factors c-jun and c-fos, by calpain. F.E.B.S. Lett. 287, 57-61.

HONG, S-C., LANZINO, G., GOTO, Y., et al. (1994). Calcium-activated proteolysis in rat neocortex induced by transient focal ischemia. Brain Res 661, 43-50.

KAMPFL, A., POSMANTUR, R., NIXON, R., et al. (1996). $\mu$-Calpain activation and calpain-mediated cytoskeletal proteolysis following traumatic brain injury. J. Neurochem. 67, 1575-1583.

KAMPFL, A., POSMANTUR, R.M., ZHAO, X., et al. (1997). Mechanisms of calpain proteolysis following traumatic brain injury: implications for pathology and therapy: a review and update. J. Neurotrauma 14, 121-133.

KONTOS, H.A. (1989). Oxygen radicals in central nervous system damage. Chem. Biol. Interact. 72, 229-255.

LI, P-A., HOWLETT, W., HE, Q.P., et al. (1998). Postischemic treatment with calpain inhibitor MDL 28170 ameliorates brain damage in a gerbil model of global ischemia. Neurosci. Lett. 247, 17-20.

LIEBETRAU, M., STAUFER, B., AUERSWALD, E.A., et al. (1999). Increased intracellular calpain detection in experimental focal cerebral ischemia. Neuroreport 10, 529-534.

MARKGRAF, C.G., VELAYO, N.L., JOHNSON, M.P., et al. (1998). Six-hour window of opportunity for calpain inhibition in focal cerebral ischemia in rats. Stroke 29, 152-158.

McCRACKEN, E., HUNTER, A.J., PATEL, S., et al. (1999). Calpain activation and cytoskeletal protein breakdown in the corpus callosum of head-injured patients. J. Neurotrauma 16, $749-761$.

McINTOSH, T.K., SAATMAN, K.E., AND RAGHUPATHI,
R. (1997). Calcium and the pathogenesis of traumatic CNS injury: cellular and molecular mechanisms. Neuroscientist $\mathbf{3}$, $169-175$.

NADLER, V., BIEGON, A., BEIT-YANNAI, E., et al. (1995). ${ }^{45} \mathrm{Ca}$ accumulation in rat brain after closed head injury, attenuation by the novel neuropretective agent HU-211. Brain Res 685, 1-11.

NATH, R., RASER, K.J., STAFFORD, D., et al., (1996). Nonerthroid $\alpha$-spectrin breakdown by calpain and interleukin $1 \beta$-converting enzyme-like protease(s) in apoptotic cells: contributory roles of both protease families in neuronal apoptosis. Biochem. J. 319, 683-690.

NATH, R., PROBERT, A. JR., McGINNIS, K.M., et al. (1998). Evidence for activation of caspase-3-like protease in excitotoxin- and hypoxia/hypoglycemia-injured neurons. J. Neurochem. 71, 186-195.

NEWCOMB, J.K., KAMPFL, A., POSMANTUR, R.M., et al. (1997). Immunohistochemical study of calpain-mediated breakdown products to (-spectrin following controlled cortical impact injury in the rat. J. Neurotrauma 14, 369-383.

NILSSON, P., HILLERED, L. OLSSON, Y., et al. (1993). Regional changes in interstitial $\mathrm{K}^{+}$and $\mathrm{Ca}^{2+}$ levels following cortical compression contusion trauma in rats. J. Cereb. Blood Flow Metab. 13, 185-192.

NIXON, R.A. (1989). Calcium activated neutral proteinases as regulators of cellular function. Implications for alzheimers disease pathogenesis. Ann. N.Y. Acad. Sci. 568, 198-208.

de OLMES, J.S., BELTRAMINO, C.A. and de OLMES-DE LORENZO, S. (1994). Use of an amino-cupric-silver technique for the detection of early and semiacute neuronal degeneration caused by neurotoxicants, hypoxia, and physical trauma. Neurotoxicol. Teratol. 16, 545-561.

POSMANTUR, R.M., HAYES, R.L., DIXON, E., et al. (1994). Neurofilament 68 and neurofilament 200 protein levels decrease after traumatic brain injury. J. Neurotrauma 11, 533-545.

POSMANTUR, R.M., KAMPFL, A, LIU, S-J., et al. (1996). Cytoskeletal derangements of cortical neuronal processes three hours after traumatic brain injury in rats: an immunofluorescence study. J. Neuropathol. Exp. Neurol. 55, 68-80.

POSMANTUR, R., KAMPFL, A., SIMAN, R., et al. (1997a). A calpain inhibitor attenuates cortical cytoskeletal protein loss after experimental traumatic brain injury in the rat. roscience $77,875-888$.

POSMANTUR, R., MCGINNIS, K., NADIMPALLI, R., et al. (1997b). Characterization of CPP32-like protease activity following apoptotic challenge in SH-SY5Y neuroblastoma cells. J. Neurochem. 68, 2328-2337.

POVLISHOCK, J.T., BUKI, A., KOIZIUMI, H., et al. (1999). Initiating mechanisms involved in the pathobiology of traumatically induced injury and interventions targeted at blunting their progression. Acta Neurochir. (Wien) Suppl. 73, 15-20. 
RAY, S.K., SHIELDS, D.C., SAIDO, T.C., et al. (1999). Calpain activity and translational expression increased in spinal cord injury. Brain Res. 816, 375-380.

RINK, A.D., FUNG, K-M., TROJANOWSKI, J.Q., et al. (1995). Evidence of apoptotic cell death after experimental traumatic brain injury in the rat. Am. J. Pathol. 147, 1575-1583.

ROBERTS-LEWIS, J.M., and SIMAN, R. (1993). Spectrin proteolysis in the hippocampus: a biochemical marker for neuronal injury and neuroprotection. Ann. N.Y. Acad. Sci. 679, 78-86.

ROBERTS-LEWIS, J.M., SAVAGE, M.J., MARCY, V.R., et al. (1994). Immunolocalization of calpain I-mediated spectrin degradation to vulnerable neurons in the ischemic gerbil brain. J. Neurosci. 14, 3934-3944.

SAATMAN, K.E., BOZYCZKO-COYNE, D., MARCY, V., et al. (1996a). Prolonged calpain-mediated spectrin breakdown occurs regionally following experimental brain injury in the rat. J. Neuropathol. Exp. Neurol. 55, 852-862.

SAATMAN, K.E., MURAI, H., BARTUS, R.T., et al. (1996b). Calpain inhibitor AK295 attenuates motor and cognitive deficits following experimental brain injury in the rat. Pro. Natl. Acad. Sci. U.S.A. 93, 3428-3433.

SAATMAN, K.E., GRAHAM, D.I., and MCINTOSH, T.K. (1998). The neuronal cytoskeleton is at risk after mild and moderate brain injury. J. Neurotrauma 15, 1047-1058.

SAATMAN, K.E., ZHANG, C., BARTUS, R.T., et al. (2000). Behavioral efficacy of post traumatic calpain inhibition is not accompanied by reduced spectrin proteolysis, cortical lesion, or apoptosis. J. Cereb. Blood Flow Metab. 20, 66-73.

SHAPIRA, Y., YADID, G., COTEV, S., et al. (1989). Accumulation of calcium in the brain following head trauma. Neurol. Res. 11, 169-172.

SHIELDS, D.C. AND BANIK, N.L. (1999). Mini-review: pathophysiological role of calpain in experimental demyelination. J. Neurosci. Res. 55, 533-541.

SIESJO, B.K. and BENGTSSON, F. (1989). Calcium fluxes, calcium antagonists, and calcium-related pathology in brain ischemia, hypoglycemia, and spreading depression: a unifying hypothesis. J. Cereb. Blood Flow Metab. 9, 127-140.

SORIMACHI, H., SAIDO, T.C., and SUZUKI, K. (1994). New era of calpain research: discovery of tissue-specific calpains. F.E.B.S. Lett. 343, 1-5.

SWITZER, R.C., III. (2000). Application of silber degeneration stains for neurotoxicity testing. Toxicol. Pathol. 28, 70-83.

SUZUKI, K. and OHNO, S. (1990). Calcium activated neutral protease structure-function relationship and functional implications. Cell Struct. Funct. 156, 1-6.

VERITY, M.A. $\mathrm{Ca}^{2+}$-dependent processes as mediators of neurotoxicity. Neurotoxicology 13, 139-148.

WANG, K.K.W. (2000). Calpain and caspase: can you tell the difference? Trends Neurosci. 23, 20-26.

WANG, K.K.W. and YUEN, P-W. (1994). Calpain inhibition: an overview of its therapeutic potential. Trends Pharmacol. Sci. 15, 412-419.

WANG, K.K.W. and YUEN, P.-W. (1999). Calapin substrates, assay methods, regulation and its inhibitory agents, in: Calpain: Pharmacologyand Toxicology of a Calcium-dependent Cellular Protease. K.K.W. Wang and P-W. Yuen (eds), Taylor \& Francis: Philadelphia, pps. 77-102.

WANG, K.K.W., NATH, R., POSNER, A., et al. (1996). An alpha-mercaptoacrylic acid derivative is a selective nonpetptide cell-permeable calpain inhibitor and is neuroprotective. Proc. Natl. Acad. Sci. U.S.A. 93, 6687-6692.

YUEN, P.-W., and WANG, K.K.W. (1996). Therapeutic potential of calpain inhibitors in neurodegenerative disorders. Exp. Opin. Invest. Drugs 5, 1291-1304.

YUEN, P.-W., and WANG, K.K.W. (1998). Calpain inhibitors: novel neuroprotectants and potential anticataract agents. Drugs Future 23, 741-749.

Address reprint requests to: Edward D. Hall, Ph.D. Neuroscience Therapeutics Pfizer Global Research and Development-Ann Arbor Laboratories 2800 Plymouth Rd. Ann Arbor, MI 48015

E-mail: edward.hall@pfizer.com 


\section{This article has been cited by:}

1. Melissa J. McGinn, Brian J. Kelley, Linnet Akinyi, Monika W. Oli, Ming Cheng Liu, Ronald L. Hayes, Kevin K.W. Wang, John T. Povlishock. 2009. Biochemical, Structural, and Biomarker Evidence for Calpain-Mediated Cytoskeletal Change After Diffuse Brain Injury Uncomplicated by Contusion. Journal of Neuropathology and Experimental Neurology 68:3, 241-249. [CrossRef]

2. Wei Jin, Handong Wang, Wei Yan, Lin Zhu, Zhigang Hu, Yasuo Ding, Ke Tang . 2009. Role of Nrf2 in Protection against Traumatic Brain Injury in MiceRole of Nrf2 in Protection against Traumatic Brain Injury in Mice. Journal of Neurotrauma 26:1, 131-139. [Abstract] [PDF] [PDF Plus]

3. Chen-Guang Yu, Aashish Joshi, James W. Geddes . 2008. Intraspinal MDL28170 Microinjection Improves Functional and Pathological Outcome following Spinal Cord InjuryIntraspinal MDL28170 Microinjection Improves Functional and Pathological Outcome following Spinal Cord Injury. Journal of Neurotrauma 25:7, 833-840. [Abstract] [PDF] [PDF Plus]

4. Inês M. Araújo, Joana M. Gil, Bruno P. Carreira, Paul Mohapel, Åsa Petersen, Paulo S. Pinheiro, Denis Soulet, Ben A. Bahr, Patrik Brundin, Caetana M. Carvalho. 2008. Calpain activation is involved in early caspase-independent neurodegeneration in the hippocampus following status epilepticus. Journal of Neurochemistry 105:3, 666-676. [CrossRef]

5. Matthew B Bevers, Robert W Neumar. 2008. Mechanistic role of calpains in postischemic neurodegeneration. Journal of Cerebral Blood Flow \& \&38; Metabolism 28:4, 655-673. [CrossRef]

6. Chen-Guang Yu, James W. Geddes. 2007. Sustained Calpain Inhibition Improves Locomotor Function and Tissue Sparing Following Contusive Spinal Cord Injury. Neurochemical Research 32:12, 2046-2053. [CrossRef]

7. Rodney Guttmann. 2007. Recent developments in the therapeutic targeting of calpains in neurodegeneration. Expert Opinion on Therapeutic Patents 17:10, 1203-1213. [CrossRef]

8. Jinglu Ai , Elaine Liu, Jianli Wang, Yonghong Chen, Julie Yu, Andrew J. Baker . 2007. Calpain Inhibitor MDL-28170 Reduces the Functional and Structural Deterioration of Corpus Callosum following Fluid Percussion InjuryCalpain Inhibitor MDL-28170 Reduces the Functional and Structural Deterioration of Corpus Callosum following Fluid Percussion Injury. Journal of Neurotrauma 24:6, 960-978. [Abstract] [PDF] [PDF Plus]

9. Zhiqun Zhang, Andrew K Ottens, Shankar Sadasivan, Firas H. Kobeissy, Tie Fang, Ronald L. Hayes , Kevin K.W. Wang . 2007. Calpain-Mediated Collapsin Response Mediator Protein-1, -2, And -4 Proteolysis after Neurotoxic And Traumatic Brain InjuryCalpain-Mediated Collapsin Response Mediator Protein-1, -2, And -4 Proteolysis after Neurotoxic And Traumatic Brain Injury. Journal of Neurotrauma 24:3, 460-472. [Abstract] [PDF] [PDF Plus]

10. Kevin KW Wang, Stephen F Larner, Gillian Robinson, Ronald L Hayes. 2007. Neuroprotection targets after traumatic brain injury. Current Opinion in Neurology 19:6, 514???519. [CrossRef]

11. Qinghua Chen, Susan Wang, Stephanie N. Thompson, Edward D. Hall, Rodney P. Guttmann. 2006. Identification and characterization of PEBP as a calpain substrate. Journal of Neurochemistry 99:4, 1133-1141. [CrossRef]

12. Brice Ongali , Farida Hellal, Donata Rodi , Michel Plotkine , Catherine Marchand-Verrecchia , Didier Pruneau , Réjean Couture . 2006. Autoradiographic Analysis of Mouse Brain Kinin B1 and B2 Receptors after Closed Head Trauma and Ability of Anatibant Mesylate to Cross the Blood-Brain BarrierAutoradiographic Analysis of Mouse Brain Kinin B1 and B2 Receptors after Closed Head Trauma and Ability of Anatibant Mesylate to Cross the Blood-Brain Barrier. Journal of Neurotrauma 23:5, 696-707. [Abstract] [PDF] [PDF Plus]

13. Arabinda Das, Eric A. Sribnick, James M. Wingrave, Angelo M. Del Re, John J. Woodward, Stanley H. Appel, Naren L. Banik, Swapan K. Ray. 2005. Calpain activation in apoptosis of ventral spinal cord 
4.1 (VSC4.1) motoneurons exposed to glutamate: Calpain inhibition provides functional neuroprotection. Journal of Neuroscience Research 81:4, 551-562. [CrossRef]

14. M. Kelly Guyton, J. Michael Wingrave, Anil V. Yallapragada, Gloria G. Wilford, Eric A. Sribnick, Denise D. Matzelle, William R. Tyor, Swapan K. Ray, Naren L. Banik. 2005. Upregulation of calpain correlates with increased neurodegeneration in acute experimental auto-immune encephalomyelitis. Journal of Neuroscience Research 81:1, 53-61. [CrossRef]

15. Y. Haranishi, R. Kawata, S. Fukuda, T. Kiyoshima, Y. Morimoto, M. Matsumoto, T. Sakabe. 2005. Moderate hypothermia, but not calpain inhibitor 2, attenuates the proteolysis of microtubule-associated protein 2 in the hippocampus following traumatic brain injury in rats. European Journal of Anaesthesiology 22:2, 140-147. [CrossRef]

16. Edward D. Hall, Patrick G. Sullivan, Tonya R. Gibson, Krissi M. Pavel, Brian M. Thompson, Stephen W. Scheff . 2005. Spatial and Temporal Characteristics of Neurodegeneration after Controlled Cortical Impact in Mice: More than a Focal Brain InjurySpatial and Temporal Characteristics of Neurodegeneration after Controlled Cortical Impact in Mice: More than a Focal Brain Injury. Journal of Neurotrauma 22:2, 252-265. [Abstract] [PDF] [PDF Plus]

17. Ines M. Araujo, Maria J. Verdasca, Ermelindo C. Leal, Ben A. Bahr, Antonio F. Ambrosio, Arselio P. Carvalho, Caetana M. Carvalho. 2005. Early calpain-mediated proteolysis following AMPA receptor activation compromises neuronal survival in cultured hippocampal neurons. Journal of Neurochemistry 91:6, 1322-1331. [CrossRef]

18. Susan M. Knoblach, Daniel A. Alroy, Maria Nikolaeva, Ibolja Cernak, Bogdan A. Stoica, Alan I. Faden. 2004. Caspase Inhibitor z-DEVD-fmk Attenuates Calpain and Necrotic Cell Death in Vitro and After Traumatic Brain Injury. Journal of Cerebral Blood Flow \& Metabolism 1119-1132. [CrossRef]

19. Ibolja Cernak, Robert Vink, JoAnne Natale, Bogdan Stoica, Paul M. Lea, Vilen Movsesyan, Farid Ahmed, Susan M. Knoblach, Stanley T. Fricke, Alan I. Faden. 2004. The ???Dark Side??? of Endocannabinoids: A Neurotoxic Role for Anandamide. Journal of Cerebral Blood Flow \& Metabolism 564-578. [CrossRef]

20. Adrian T. McCollum, Faegheh Jafarifar, Roy Chan, Rodney P. Guttmann. 2004. Oxidative stress inhibits ionomycin-mediated cell death in cortical neurons. Journal of Neuroscience Research 76:1, 104-109. [CrossRef]

21. Edward D. Hall , Megan R. Detloff , Kjell Johnson, Nancy C. Kupina . 2004. Peroxynitrite-Mediated Protein Nitration and Lipid Peroxidation in a Mouse Model of Traumatic Brain InjuryPeroxynitrite-Mediated Protein Nitration and Lipid Peroxidation in a Mouse Model of Traumatic Brain Injury. Journal of Neurotrauma 21:1, 9-20. [Abstract] [PDF] [PDF Plus]

22. F. Hellal , D. Pruneau , B. Palmier, P. Faye , N. Croci , M. Plotkine , C. Marchand-Verrecchia . 2003. Detrimental Role of Bradykinin B2 Receptor in a Murine Model of Diffuse Brain InjuryDetrimental Role of Bradykinin B2 Receptor in a Murine Model of Diffuse Brain Injury. Journal of Neurotrauma 20:9, 841-851. [Abstract] [PDF] [PDF Plus]

23. J. Michael Wingrave, Kurt E. Schaecher, Eric A. Sribnick, Gloria G. Wilford, Swapan K. Ray, Debra J. Hazen-Martin, Edward L. Hogan, Naren L. Banik. 2003. Early induction of secondary injury factors causing activation of calpain and mitochondria-mediated neuronal apoptosis following spinal cord injury in rats. Journal of Neuroscience Research 73:1, 95-104. [CrossRef]

24. Shu-Xin Zhang, Vimala Bondada, James W. Geddes . 2003. Evaluation of Conditions for Calpain Inhibition in the Rat Spinal Cord: Effective Postinjury Inhibition with Intraspinal MDL28170 MicroinjectionEvaluation of Conditions for Calpain Inhibition in the Rat Spinal Cord: Effective Postinjury Inhibition with Intraspinal MDL28170 Microinjection. Journal of Neurotrauma 20:1, 59-67. [Abstract] [PDF] [PDF Plus]

25. Nancy C. Kupina, Megan R. Detloff, Satavisha Dutta, Edward D. Hall. 2002. Neuroimmunophilin Ligand V-10,367 Is Neuroprotective After 24-Hour Delayed Administration in a Mouse Model of Diffuse Traumatic Brain Injury. Journal of Cerebral Blood Flow \& Metabolism 1212-1221. [CrossRef] 